Dicenda. Estudios de lengua y literatura españolas

ISSN-e: $1988-2556$

http://dx.doi.org/10.5209/DICE.62137

\title{
El autor en conflicto en las poéticas explícitas del siglo XX
}

\author{
Rocío Badía Fumaz ${ }^{1}$
}

Recibido: 18 de noviembre de 2016 / Aceptado: 5 de septiembre de 2017

Resumen. A partir del cambio en la noción de autor que tiene lugar en la década de los sesenta del pasado siglo, este trabajo aborda el conflicto que surge al tratar de comprender desde esta perspectiva la idea de autor en las poéticas explícitas, un género que tradicionalmente se funda en la estrecha identificación entre autor textual y autor biográfico. Se cuestiona la idea de un autor previo al texto y se explora la construcción de la figura de autor, mostrando todas sus complejidades.

Palabras clave: autor literario; imagen de autor; poéticas explícitas; Roland Barthes; Michel Foucault.

\section{[en] The Author in Conflict in the 20th Century Explicit Poetics}

\begin{abstract}
Beginning with the new approaches to understanding author in the decade of the 60 's, this work aims to present the conflict which this notion set out when it is confronted with explicit poetics, a genre with an apparently unbreakable link between textual author and biographical author. It is questioned the idea of a previous author in explicit poetics and it is analysed the construction of an image of the author in these texts, showing the complexity of the concept.
\end{abstract}

Keywords: literary author; image of the author; explicit poetics; Roland Barthes; Michel Foucault.

Sumario: 1. Introducción; 2. Una nueva visión del autor: Roland Barthes y Michel Foucault; 3. El autor en las poéticas explícitas; 4. Una perspectiva sociológica; 5. Conclusiones.

Cómo citar: Badía Fumaz, R. (2018). El autor en conflicto en las poéticas explícitas del siglo XX, en Dicenda. Estudios de Lengua y Literatura Españolas, 36, 45-65.

\section{Introducción}

El objetivo de este trabajo es indagar en el cambio de la imagen de autor que tiene lugar en las últimas décadas ${ }^{2}$, desde un punto de vista teórico pero escogiendo para

$1 \quad$ Universidad de Deusto rociobadia@deusto.es.

2 La bibliografía reciente dedicada al estudio del autor tanto desde la Teoría de la Literatura como desde la Sociología no deja de incrementarse. Algunos ejemplos de este auge son el número monográfico de la revista Tropelías "La autoría a debate: textualizaciones del cuerpo-corpus" coordinado por Aina Pérez Fontdevila y Meri Torras Francés (2015), con contribuciones de varios autores que abordan aspectos diversos de esta problemática; el volumen compilado por las mismas autoras Los papeles del autor/a. Marcos teóricos sobre la autoría literaria (2016), y la antología de Juan Zapata La invención del autor. Nuevas aproximaciones al estudio sociológico y discursivo de la figura autorial (2014). 
su esclarecimiento un género donde el autor literario tiene un peso considerable: las poéticas de autor o poéticas explícitas, breves textos de tipo ensayístico donde los escritores exponen sus ideas literarias ${ }^{3}$.

Confrontar el desarrollo filosófico de la noción de autor que surge en la década de los sesenta con las poéticas en las que autores literarios manifiestan desde el yo su interpretación de la literatura y de su propia obra puede parecer problemático. Sin embargo, hacer dialogar la reflexión acerca de la desaparición del autor con textos construidos justamente sobre la presencia del mismo permite vislumbrar hasta qué punto los discursos filosóficos iniciados por Roland Barthes en "La muerte del autor" y Michel Foucault en ¿Qué es un autor? son exitosos, planteando tanto las posibilidades interpretativas que ofrecen como los límites de los mismos.

La primera pregunta a responder, por tanto, sería la siguiente: ¿cómo se puede comprender el conflicto en torno a la muerte del autor en unos textos de apariencia autobiográfica que sólo tienen sentido merced a la existencia previa y reconocida de su autor? Una vez solventado este interrogante, surge un cuestionamiento histórico que nos lleva a plantear si la imagen de autor que emerge de las poéticas siempre se ha entendido del mismo modo. La respuesta a esta segunda cuestión es, claro, negativa. Sólo a partir de la misma época en la que se ponen en entredicho los fundamentos de la noción de autor este elemento aparece de forma conflictiva en las poéticas explícitas, adquiriendo variados matices y funciones que permiten observar en el género la vuelta de tuerca que la idea de autor sufrió en la década de los sesenta.

\section{Una nueva visión del autor: Roland Barthes y Michel Foucault}

Señala Roland Barthes en "La muerte del autor" (1967) que la emergencia del autor sólo es posible en complicidad con la emergencia del individuo. Aunque quizá la conciencia de individualidad del escritor emerge con anterioridad, como propone Pedro Ruíz Pérez en La rúbrica del poeta. La expresión de la autoconciencia poética de Boscán a Góngora (2009), la verdadera exaltación del individuo tiene lugar en el Romanticismo, momento clave, además, para la aparición de toda una variada serie de géneros del yo, que abonarán el camino primero para los manifiestos y luego para las poéticas de autor o poéticas explícitas.

Frente a la estela de la tradición de la que reniega Barthes, donde el autor se comprende en términos temporales como previo a la obra, y por tanto piedra angular de su interpretación y sentido 4 , se encuentra el esperable momento de reacción posterior contra la preeminencia del autor. El éxito de este revulsivo tuvo como consecuencia que hasta hace apenas un par de décadas acudir al estudio del autor resultara, cuan-

3 Hemos elegido trabajar con autores literarios debido a la gran cantidad de textos de este tipo disponibles; sin embargo, es obvia la existencia de poéticas explícitas en las diferentes artes, por lo que puede extenderse su estudio a otras manifestaciones artísticas. El término de poéticas explícitas para referirse a estos textos, que caracterizaremos brevemente en el segundo capítulo, convive con otros como poéticas de autor, poéticas individuales, autopoéticas y otras formulaciones similares. Para una discusión sobre el problema del nombre y su constitución como género puede acudirse al trabajo de Rocío Badía Fumaz "Las poéticas explícitas como género" (2018).

4 "[L]a explicación de la obra se busca siempre en el que la ha producido, como si, a través de la alegoría más o menos transparente de la ficción, fuera, en definitiva, siempre, la voz de una sola y misma persona, el autor, la que estaría entregando sus "confidencias"” ( Barthes, 1987b: 66) En las poéticas explícitas y otros textos autopoéticos este fenómeno se vuelve explícito. 
do menos, cuestionable, y muy a menudo se convirtiera en una opción fuertemente criticada por el estrecho horizonte que, efectivamente, habían planteado los estudios literarios hasta los años sesenta del pasado siglo 5 . Pero sigamos con Barthes, como quicio entre ambos momentos y responsable directo, probablemente, tanto del rechazo del estudio del autor como del auge que su abordaje está teniendo en los últimos años.

Supone "La muerte del autor" paradójicamente un incontestable broche de oro para la crítica y análisis literarios que se habían fundado sobre el rastreo de la voluntad última del autor para desentrañar el sentido de la obra. Decimos paradójicamente porque con este artículo el filósofo francés resalta la importancia de una categoría que pretende eliminar del trabajo científico. El autor, señala, nunca es previo a la obra, sino que se construye en la misma, en un plano idéntico a la actualización gramatical, propone, que tiene lugar en cada oración por ejemplo con los deícticos ${ }^{6}$. El autor tal como se había venido concibiendo queda desmantelado en la escritura: "la escritura es la destrucción de toda voz, de todo origen" (Barthes, 1987b: 65), pues cuando "el autor entra en su propia muerte, comienza la escritura" (Barthes, 1987b: 66). Esta limitación a un plano puramente textual impone un límite insalvable entre biografía y lingüística. El autor no volverá a ser nunca el autor biográfico, extratextual, finito. Por lo demás, la construcción simultánea de autor y obra desemboca en una pluralidad hipotética de autores, tantos como lecturas, que abre la puerta de par en par a la Estética de la Recepción desarrollada por la Escuela de Constanza.

El autor, para Barthes, ocupa sólo lo que ocupa el texto: no lo desborda, no lo antecede, por tanto el crítico no puede buscar fuera del texto lo que sólo existe dentro de él. La muerte del autor, aunque en otras ocasiones el filósofo escoja hablar de alejamiento, elimina en consecuencia la posibilidad de un sentido previo de la obra. El sentido se va reconfigurando en los mismos términos que el autor. Surge del texto y es instaurado en cada lectura por la instancia que a partir de ese momento será reificada, el lector, limitado también a categoría textual: "la unidad del texto no está en su origen, sino en su destino, pero este destino ya no puede seguir siendo personal: el lector es un hombre sin historia, sin biografía, sin psicología; él es tan sólo ese alguien que mantiene reunidas en un mismo campo todas las huellas que constituyen el escrito" (Barthes, 1987b: 71).

La desaparición del autor como autoridad interpretativa, opción seguida intensamente por casi toda la crítica occidental desde ese momento, deja la problemática del autor como una cuestión que sólo interesa abordar para continuar constatando su absoluta falta de necesidad. Son frecuentes entonces las afirmaciones académicas que reiteradamente recuerdan la bondad de esa falta de autor, construyendo sus discursos, sin embargo, sobre la misma categoría cuya desaparición celebran. Y es que pese a la contundente renuncia al autor como elemento clave de la obra, la fascinación

5 En este sentido es interesante la siguiente constatación de Arturo Casas: "Cualquier observador del rumbo actual de los estudios literarios constata que la excedencia del autor ha tocado a su fin. Pero la inercia del siglo pesa lo suyo, y no es raro que el investigador que se acerca al ámbito de problemas centrados en la autoría acabe por tener la impresión de que participa apenas en una visitatio sepulchri" (Casas, 2000: 209).

6 En otros lugares abunda Barthes en la misma idea, como puede verse en la siguiente cita del artículo "Escribir, ¿un verbo intransitivo?”: "el lenguaje no puede ser considerado como un simple instrumento, utilitario o decorativo, del pensamiento. El hombre no preexiste al lenguaje, ni filogenéticamente ni ontogenéticamente. Nunca topamos con ese estado en que el hombre estaría separado del lenguaje, y elaboraría este último para 'expresar' lo que pasa en su interior: es el lenguaje el que enseña cómo definir al hombre, y no al contrario" (Barthes, 1987a: 25). 
por esta noción cada vez más difuminada ha mantenido viva, a favor o en contra, su presencia en el panorama literario. Llama la atención por ejemplo, y desarrollaremos este punto con mayor cuidado en páginas siguientes, la coincidencia temporal que existe entre la publicación de las reflexiones de Barthes y el auge editorial de las poéticas explícitas, textos breves de carácter ensayístico donde, como hemos indicado, un autor literario aborda cuestiones relacionadas con la literatura en general, el proceso creativo y las claves interpretativas de la obra propia.

Puede señalarse que en este caso, como en tantos otros, teoría filosófica y práctica editorial -que no pone de relieve otra cosa que el interés del público lector- están disociadas. Desde la reflexión teórica del autor literario biográfico se asimilan parte de estas cuestiones filosóficas, optándose por originales soluciones que permiten vislumbrar incluso en un género construido sobre la importancia del autor esa muerte del autor anunciada. Pero es también la reflexión filosófica agente activo a la hora de mantener vivo el interés por la categoría señalada. Apenas dos años después de la publicación de "La muerte del autor" de Roland Barthes, Michel Foucault pronuncia en la Sociedad Francesa de Filosofía otro de los textos fundacionales que contribuyeron al giro interpretativo de la categoría, su famosa exposición ¿Qué es un autor? (1969).

Foucault, incitado por las críticas que había levantado la publicación de Las palabras y las cosas (1966) a raíz del libre uso que hacía de los autores en los que apoyaba su trabajo, centra su mirada en indagar en "la relación del texto con el autor, la manera en que el texto apunta hacia esa figura que le es exterior y anterior, al menos en apariencia" (Foucault, 2010: 11). Ya en esta declaración del objetivo de sus planteamientos se percibe que la propuesta de Barthes no había limitado ni el interés ni el alcance de la reflexión acerca del autor, volviendo Foucault a cuestionar el tema desde los mismos comienzos: la asumida separación tradicional entre autor y obra. Inmediatamente después acude a la sentencia de Beckett "qué importa quién habla" (Foucault, 2010: 11) para conectar con el alejamiento del autor planteado por Barthes, reformulado aquí en los siguientes términos: "no se trata de la aprensión de un sujeto en un lenguaje; se trata de la apertura de un espacio donde el sujeto que escribe no deja de desaparecer" (Foucault, 2010: 12).

El hueco que deja esta desaparición plantea un dilema todavía más profundo, el de la existencia de la obra. Señala Foucault que con la desaparición del autor se pierde el elemento que convierte en obra una obra: “QQué es entonces esa curiosa unidad que designamos con el nombre de obra? ¿Con qué elementos está compuesta? ¿No es acaso una obra lo que ha escrito quien es un autor?" (Foucault, 2010: 14) Incluso la existencia del autor no permite comprender el concepto de obra, pues no todo lo escrito por un autor puede entenderse como tal (Foucault, 2010: 14-15). Para solventar estas dificultades Foucault propone la utilidad de un concepto, la funciónautor, que pueda llenar así el hueco dejado por el autor permitiendo el estudio de "las funciones libres que esa desaparición hace aparecer" (Foucault, 2010: 17). Una obra, un discurso que contenga entonces la función-autor, tendrá una serie de características, cuatro en concreto, planteadas por el filósofo: convierte a la obra en un objeto de apropiación, presenta variaciones espacio-temporales en el modo en que aparece

$7 \quad$ Frente a Foucault, Philippe Lejeune en El pacto autobiográfico y otros ensayos propone entender al autor como el que ha escrito una obra. Sólo la escritura de una obra, acto previo y necesario, puede constituir al autor (Lejeune, 1994: 61). 
la función-autor, existen unas reglas complejas para la construcción del autor, y evidencia que no puede relacionarse de forma directa y exclusiva la función-autor con un único individuo. Las características que nos van a interesar más serán estas dos últimas, los mecanismos que permiten construir un autor (o una imagen de autor), que comprenderemos con Juan Zapata bajo la noción de proyecto autorial (Zapata, 2011: 48), y la pluralidad de ego propuesta por el filósofo francés (Foucault, 2010: 28-30).

Lo que nos atañe en definitiva es observar cómo estos planteamientos que hemos abordado someramente, el de la construcción del autor por el texto y el del continuo desaparecer del autor en su obra, funcionan en uno de los géneros literarios más regidos por la fuerza del yo autor, las poéticas explícitas, que sólo tienen sentido merced a su vinculación estrictísima con un autor biográfico delimitado y reconocible ${ }^{8}$.

\section{El autor en las poéticas explícitas}

La explícita atención del autor a su proceso de creación y la manifestación de la visión o idea que tiene de sí mismo en tanto creador son una constante en la tradición occidental. Sintetizando brevemente, puede decirse que hasta el Romanticismo la reflexión del autor lleva implícita la defensa de una posición teórica que, si bien tiene un origen personal, se muestra como exponente necesario para una universalidad de autores anteriores - que han acertado o por el contrario no han logrado, desde el punto de vista del autor que reflexiona, una creación artística exitosa- e hipotéticos autores posteriores, respecto de los cuales busca defender su propuesta como la más idónea y, por ende, digna de imitar.

Por esta razón, las poéticas de autores artísticos anteriores al Romanticismo están próximas a las poéticas universalistas donde filósofos, retóricos, autoridades en general al fin y al cabo, plantean principios y reglas que debe seguir toda creación artística que persiga un valor estético. En el ámbito de la literatura puede verse la evolución del pensamiento literario de la mano de estos autores de reglas y manuales, de valoraciones estéticas, desde el siglo XIII hasta la actualidad, incluyendo autores literarios y no literarios, en Las ideas literarias (1214-2010), de José María Pozuelo Yvancos. Pese a la diversidad autorial que evidencia el estudio, donde los autores van "desde un rey sabio o un poeta hasta un catedrático, un periodista o un dramaturgo" (Pozuelo Yvancos, 2011: xix), en todos los ejemplos se percibe un reconocimiento externo como autoridad merced a su pensamiento, e, incluso una autopercepción como autoridad construida sobre la idea de que $s u$ pensamiento literario es un pensamiento valioso también para los demás. Por esta razón el autor difunde de forma explícita -esto es, mediante su formalización - unas ideas literarias que aspira a que expliquen el pasado e influyan en el presente y en el futuro de la labor creativa literaria.

La validez universal de los planteamientos no parece ser puesta en duda. A esto responde un estilo, el de los textos a los que nos referiremos como poéticas universalistas, siguiendo la terminología propuesta por Adriana de Teresa (de Teresa, 2002), fundamentalmente objetivo, con escasas referencias al yo, con una presencia sustancial de lenguaje académico y uso de metalenguaje, y una función normativa

8 Escogemos el ámbito de la literatura, pero como advierte Gianni Vattimo (1993) y el propio Foucault (2010: 30-31) es un fenómeno que también ocurre en las diferentes artes. 
que supera la descriptiva y explicativa. La validez del discurso se fundamenta en las razones que lo construyen, además de en la autoridad académica -esta idea es importante- del autor.

¿Qué ocurre cuando la poética universalista viene de un autor literario que, por lo tanto, no es primeramente reconocido como una autoridad por su pensamiento sino por su labor creadora? En estos casos, dentro de los que podemos señalar ejemplos señeros como la Epístola a los Pisones de Horacio o el Arte nuevo de hacer comedias de Lope de $\mathrm{Vega}^{9}$, el autor se ha desdoblado convirtiéndose en académico, en emisor y sancionador de propuestas explicativas que buscan reconocimiento universal tanto en tiempo como en espacio. Es a partir del Romanticismo cuando se produce el reconocimiento de una individualidad que permite el surgimiento de otro tipo de textos, las poéticas explícitas ${ }^{10}$, donde esta ambición de universalidad queda, cuando menos, diluida.

Se produce entonces un cambio en el mecanismo de legitimación de las poéticas. De la validez emergente de una voz impositiva, que sólo puede surgir de cierta escasez de este tipo de manifestaciones, la validez de las poéticas explícitas se construye sobre la autoridad individual del autor. Este carácter individual de la voz reflexiva es reivindicado con firmeza por la mayor parte de los autores. La propia conciencia de individualidad permite que cada vez más autores manifiesten su propia concepción de lo literario, multiplicándose la cantidad de textos a un ritmo progresivamente acelerado. Pero los cambios no sólo serán cuantitativos. Los rasgos que caracterizan las poéticas se modifican a su vez. Ya no se trata de imponer o convencer, sino de describir, de explicar la propia vivencia individual de la creación literaria, para lo cual, evidentemente, se necesita un autor necesariamente literario. Ésta será una de las diferencias tajantes entre poéticas universalistas y poéticas particulares.

Pese a la creciente atención que han suscitado estos textos en los últimos años, su caracterización resulta todavía problemática. Como propuesta operativa para trabajar con ellos desligándolos de géneros semejantes, como las aludidas poéticas universalistas, pero también como las artes poéticas, los manifiestos o la poética implícita que se extrae de los textos puramente literarios, pueden señalarse los siguientes rasgos suficientes y necesarios: a) autor literario; b) coincidencia de sujeto y objeto de investigación: el autor reflexiona sobre sí mismo; c) tema relacionado con la literatura; d) tipo de texto no literario, a menudo de carácter ensayístico (Badía Fumaz, 2018: 621 y sigs.). Puede percibirse que, de estos rasgos, son los dos primeros aquellos más necesarios de explorar a la hora de valorar la imagen y proyecto autoriales que se desprende de las poéticas explícitas contemporáneas.

9 De una forma no tan clara, ya en el siglo XX, puede tomarse en consideración las poéticas prácticamente universalistas de los poetas profesores de la Generación del 27 (Pedro Salinas, Jorge Guillén, Dámaso Alonso, etc.), de José Ángel Valente con Las palabras de la tribu u Octavio Paz y El arco y la lira, para comprobar cómo el discurso universalista, aún de los propios autores, se mantiene, y presenta unos rasgos distintos de otras manifestaciones autoriales que consideraremos como poéticas explícitas. Puede señalarse ya en este momento cómo se aprecia un cambio en los títulos de las obras, pues pese a su voluntad universal no pueden identificarse con las poéticas universalistas previas regidas por una voluntad aseverativa y una pretendida validez universal con mucho menor peso en las poéticas del siglo XX. De todos modos, es más que frecuente que convivan en estos autores, en la mayor parte de los casos, dos modalidades de reflexión explícita sobre el pensamiento literario, una de tendencia universalista y otra de tendencia individualista, caracterizada por un punto de vista subjetivo que condiciona el tratamiento de los temas.

10 Ver Gianni Vattimo (1993: 47) y Pierre Popovic (1993: 107). 
La necesidad de que el autor sea un autor literario se despliega en varias consideraciones sobre el mismo, que se pueden reunir en dos perspectivas fundamentales. Por un lado, nos recuerda que la poética explícita surge de un doble posicionamiento: el autor frente a sí mismo y el autor frente al mundo, esto último por el mero hecho de ser una figura pública, inmersa en un sistema literario que comprende al lector, el contexto editorial e histórico, y, por qué no, un posicionamiento último frente a la Historia literaria con mayúsculas en los casos más destacados. Por otro, evidencia la interesante superposición que convierte la poética explícita en un género propicio para el estudio del autor: en él se encuentra un autor reflexionando sobre sí mismo en su papel de autor y sobre su papel de autor. Entiéndase entonces casi como crisol del proyecto autorial.

Advertir estos textos como un género oportuno para el estudio de esta cuestión depende directamente de reconocer la idea de autor como auténtico eje fundacional del género. Sin autor, es decir, sin un escritor reconocible como autor incluso antes de la escritura de una poética explícita, no sólo se pierde el sentido del texto, sino que se imposibilita su aparición. No es factible una poética explícita anónima o de un autor no literario, precisamente porque es su carácter de autor literario el que permite la escritura y posterior publicación del texto.

Puede interpretarse entonces este tipo de obras como instancias reafirmadoras del autor. Por parte del autor, porque se reconoce como tal y confía en su posición en el panorama editorial como autorizada voz de opinión, pero también por parte de la recepción, en tanto que el lector, y por extensión el mercado editorial, busca este tipo de obra. Y la busca, precisamente, porque reconoce al autor como autor. No en vano la poética explícita está sustentada por la excepcionalidad del autor, pues su éxito y su sentido radican en ello, en su reconocimiento y valor como autor literario cuya voz debe ser escuchada. Si esta jerarquía, esta diferenciación, desaparece, la poética explícita no tiene, en principio, sentido.

Yendo un paso más allá, puede surgir la pregunta acerca del tipo de sociedad que acoge positivamente estos textos. Como se ha adelantado, hay una gran distancia entre el éxito de las reflexiones sobre la desaparición del autor y el efectivo interés por manifestaciones autoriales que se percibe en España en la misma época. El origen del género en su forma actual puede situarse allá por las primeras décadas del siglo XX, cuando la voluntad de colectividad que impera en los manifiestos se diluye en la atomización de las poéticas explícitas, como efecto del progresivo aumento de la individualidad iniciado en el Romanticismo ${ }^{11}$.

Dominique Maingueneau detalla así este proceso en su artículo "Escritor e imagen de autor":

Por ejemplo, el papel crucial desempeñado por los manifiestos durante los siglos XIX y XX es indisociable de la existencia de un campo literario que se quiere autónomo: cada grupo se constituye ostentosamente en torno a una cierta definición de lo que es la "verdadera" literatura. Lo que concierne al trabajo de "figuración" y de "configuración" conoce entonces un desarrollo sin precedentes: vemos proliferar los textos autobiográficos y los comentarios de los escritores sobre su obra y el Arte. Dado que la competencia entre posicionamientos se exacerba y se teatraliza, y que las definiciones de la actividad literaria son radicalmente inciertas, el pro- 
ductor está abocado a multiplicar los textos que moldearán una imagen de autor que se quiere singular. Ya no estamos en un régimen discursivo en el cual un cierto número de normas se imponen a los escritores, sino en un universo en el cual el escritor debe constantemente legitimar su proceso creativo elaborando una imagen de autor a la medida de su obra (Maingueneau, 2015: 26).

En España puede situarse en la década de los 50 del pasado siglo un pico de actividad que se mantendrá en las décadas posteriores. Una muestra de ello puede encontrarse en la selección de poéticas reunidas por Pedro Provencio en su antología de dos volúmenes Poéticas españolas contemporáneas. La generación del 50 y Poéticas españolas contemporáneas. La generación del 70 (Provencio, 1988a y 1988b), que evidencia el origen primero de la mayoría de los textos: su aparición inicial en antologías poéticas ${ }^{12}$. Es esta forma de difusión de la nueva poesía una práctica habitual en la época. Como convención, el antólogo requiere de cada autor una breve pieza de tipo ensayístico que sirva de introducción a los poemas seleccionados. No son extraños, de todos modos, otros tipos de texto que conformen la poética explícita, por ejemplo prólogos, epílogos, artículos, columnas periodísticas, etc. En todos los casos, el autor es requerido, en tanto que autor, a reflexionar sobre sí mismo y su propia obra.

Respecto a su conveniencia para el estudio del autor, Juan Zapata propone sustituir la noción de Foucault de función-autor por la idea de proyecto autorial, concebido como el estudio sistemático de la misma a partir de

tres movimientos inseparables: 1) los modos de inscripción de la "presencia autorial" tanto en los textos: novelas, poesía, teatro, etc., como en los paratextos: correspondencias, autobiografias, prefacios, manifiestos, etc. 2) las situaciones de enunciación de dichos discursos en tanto manifestaciones de una posición particular en el campo literario y 3) la recepción y modos de circulación de éstos (Zapata, 2011: 48).

Este proyecto autorial, que como señala Zapata ha recibido otros nombres, como postura (Meizoz) o escenografía autorial (José-Luis Díaz), tiene que ver no sólo con la obra literaria o artística, sino también con los textos de tipo o contenido programático de los que también son responsables los autores ${ }^{13}$. Entre los mencionados por Zapata no se encuentran -pero deberían encontrarse- las poéticas explícitas, género

12 Cabe apuntar que las antologías siempre son sancionadoras, en el sentido de que contribuyen a configurar el campo literario, en términos de Pierre Bourdieu. El mero hecho, ajeno al autor, de ser seleccionado para formar parte de una antología ya de por sí incide en la imagen de autor.

13 En un sentido muy parecido se manifiesta Dominique Maingueneau: "Se pueden identificar a priori dos zonas de activación, estrechamente ligadas, de una 'imagen de autor':

- La que concierne al texto.

- La que concierne al actor, cuyo comportamiento se apoya y actúa sobre las representaciones colectivas de lo que es la actividad normal de escritor en un lugar y en un momento dados. Retomando los términos utilizados en $L e$ Discours littéraire, podemos decir que este actor se libra a un doble trabajo de 'configuración' y de 'figuración' en función de la imagen que pretende modelar. La ‘configuración' está orientada hacia el ajuste de la obra; pasa por varios géneros: manifiestos, debates, escritos sobre otras artes, prefacios a obras de otros escritores... Permite reorientar la trayectoria de conjunto en la cual se inscribe cada obra singular: ser escritor es también gestionar la memoria interna de sus textos y de sus actividades anteriores, y reorientarlas en función de un porvenir. A este trabajo de 'configuración' se mezcla el trabajo de 'figuración' a través del cual el actor, en cierto modo, se pone en escena como escritor: viaja o no, vive retirado en el campo o en el centro de una gran ciudad, sale en televisión o esconde su cara, concede entrevistas a la prensa escrita, etc." (Maingueneau, 2015: 21). 
que vemos como el más adecuado precisamente para valorar la imagen de autor, al ser puramente autorreflexivo dentro del ámbito de lo literario. Frente a la autobiografía o la correspondencia, la poética explícita reflexiona sobre el autor como creador, no como hombre en general. Los prefacios y manifiestos sin embargo sí pueden considerarse dentro de los géneros autopoéticos, en el primer caso incluso plenamente dentro de las poéticas explícitas.

Además de la atención hacia la figura autorial que el éxito del género pone de manifiesto, en abierta contradicción con las posturas filosóficas que desde la teoría reclaman un alejamiento de la misma, ciertos rasgos de estos textos los hacen susceptibles de estudiar en ellos no sólo la imagen de autor sino también el cambio que se opera en ésta en torno al cambio de siglo, emergiendo un creador cada vez más legitimado por la acción de crear que por la obra creada. Pero vamos a atender en primer lugar a los rasgos relacionados con el autor que caracterizan casi todas las poéticas, después de presentar dos ejemplos concretos que den una idea general del tipo de texto tal como se presentaba en las décadas de los cincuenta y sesenta. El primero de los textos lo firma Jaime Gil de Biedma, y apareció en 1959 como prólogo a Compañeros de viaje:

Ser escritor lento sin duda tiene sus inconvenientes. Y no sólo porque contraría esa legítima impaciencia humana por dar remate a cualquier empresa antes que del todo olvidemos el afán y las ilusiones que en ella pusimos, sino también porque imposibilita, o al menos dificulta, la composición de cierto género de obras, de aquellas concebidas en torno a una primera intuición a la que el escritor tozudamente supedita el mundo de sus solicitudes diarias: semejante sacrificio resulta soportable por una temporada más o menos larga, pero habitualmente más corta que la que a nosotros, los escritores lentos, nos toma el escribir un número de versos suficiente (Gil de Biedma, 1975: 15).

El segundo de los ejemplos, también de Gil de Biedma, data de 1965 y se titula "Poética":

Escribir un poema es aspirar a la formulación de una relación significativa entre un hombre concreto y el mundo en que vive. En principio, la poesía me parece una tentativa, entre otras muchas, por hacer nuestra vida un poco más inteligible, un poco más humana. Para mí, el poema empieza en una composición de lugar y acaba en una síntesis: la invención de esa relación significativa. Invención a la vez en el sentido etimológico de hallazgo o descubrimiento de algo ya existente -y que por tanto no se alumbra ex nihilo en mi cabeza- y en el de creación imaginativa (Gil de Biedma, 1965: 355).

Además de las características primarias imprescindibles, uno de los rasgos de interés más evidentes es la escritura desde el yo. Así, el autor se hace patente en ese uso de la primera persona que es distintivo de las poéticas explícitas, y que se traduce en fórmulas como las que aparecen en los ejemplos anteriores: "a nosotros, los escritores lentos, nos toma el escribir un número de versos suficiente", "la poesía me parece una tentativa”, “[p]ara mí, el poema empieza en una composición de lugar”.

Esta primera persona tienta al lector a establecer una identificación entre el autor biográfico y la instancia gramatical que se despliega en la conjugación del verbo y 
los pronombres personales. ¿Pero quién es ese yo? Como ha quedado claro, ese yo sólo tiene interés si se produce una identificación estricta con el nombre de autor, sólo así adquiere valor el texto. Esta primera persona, que rara vez, aunque puede ocurrir, se oculta ${ }^{14}$ bajo otras formulaciones, parece querer responder a la pregunta que Foucault pone en boca de Beckett: ¿qué importa quién habla? Ese yo reclama en cada aparición la importancia de la cuestión, el desvelamiento de quién está oculto en el pronombre personal de primera persona. En este sentido, la legitimación del texto la da esa identificación que el lector establece entre primera persona gramatical y el nombre de autor que encabeza el texto. Es más, el discurso sólo tiene importancia, como hemos dicho, debido a esta vinculación.

Otra de las particularidades relacionadas con el autor que aparece de forma privilegiada en las poéticas explícitas es la coincidencia de sujeto y objeto: el interés de la reflexión del sujeto de la escritura es el propio sujeto, que se convierte en objeto de la misma. El yo autor es objeto de análisis, o, cuando esto no ocurre de forma directa, condiciona el análisis, que está fuertemente marcado por la subjetividad. El yo autor es tema del texto, influyendo en la forma de aproximación textual al mismo. Investigador privilegiado debido a la cercanía con lo investigado, el lector le concede el privilegio de elevar a objetividad lo que no es sino una presencia asfixiante del sujeto.

Por supuesto, esta supuesta objetividad se circunscribe a lo que atañe a la opinión del autor. Frente a las poéticas universalistas o académicas, el escritor en sus poéticas explícitas tiende a reclamar la individualidad de sus manifestaciones ensayísticas. Lo que en éstas se expone sólo tiene validez para el propio autor que las expresa. Tomando los ejemplos citados, Gil de Biedma restringe sus afirmaciones a los escritores lentos, encontrándonos un primer paso de individualización: lo expuesto no vale para cualquier autor, sino para aquellos con características creativas asimilables a las del autor Gil de Biedma. En el segundo fragmento aparece la versión más frecuente de esta individualización del discurso, aquella que construye la exposición desde el punto de vista exclusivo de la persona que habla, característica que heredan las poéticas explícitas del ámbito genérico del ensayo, que sólo puede aparecer con la emergencia del yo. Se traduce en formulaciones como "me parece", pero sobre todo en marcadores que limitan el alcance de lo expuesto, como las dos palabras que parecen servir de advertencia contra la extrapolación de sus palabras a otros autores, ese "[p]ara mí". Continuamos advirtiendo la continua referencia al autor sobre la que se construyen las poéticas.

La constante llamada a la individualidad sitúa el discurso en unas coordenadas espaciales y temporales, aquellas que limitan y dan forma al individuo que habla. El contenido del discurso está fuertemente vinculado a quien habla, entrando en el terreno de la opinión e introduciendo otro de los rasgos típicos del género, la provisionalidad. Al contrario que las poéticas universalistas, el escritor de una poética

14 El uso de la segunda persona, caso de encontrarse algún ejemplo, será completamente anecdótico. El uso de la tercera persona altera el carácter del texto. Cuando se utiliza para hablar de otro autor literario se matiza el carácter de poética explícita del texto. En efecto, en el caso de los estudios de un autor literario sobre otros autores, o de reseñas sobre obras publicadas, pese a no encontrarnos ante una poética explícita canónica sí permite la indagación en la idea de autor sostenida por el escritor, usualmente por una comparación con el autor estudiado o por la relevancia otorgada a unas u otras cuestiones. Silvina Celeste Fazio se refiere a este mecanismo como un "modo delegado de autoconfiguración" (Fazio, 2010). "El uso de construcciones impersonales, por otro lado, es usual cuando el autor quiere ocultarse, por ejemplo, para construir una poética de tipo universalista, como puede ocurrir en buena parte de los textos ensayísticos de José Ángel Valente. Es "la mirada de la historia" o "la mirada de Dios, es decir, de la eternidad", dirá Lejeune (Lejeune, 1994: 53). 
explícita conoce, asume y, en cierto sentido, defiende, el carácter restringido de lo expuesto.

El autor reconoce una provisionalidad en sus argumentos, en tanto que a la limitación que impone la individualidad del discurso se suma que éste a su vez es cambiante. Una poética explícita recoge un momento particular del pensamiento literario de un autor, quien es plenamente consciente de lo variable de éste ${ }^{15}$. Debido a ello, no son infrecuentes las llamadas de atención sobre este punto, como sugiere la advertencia "[e]n principio", que encontramos en la segunda cita, palabras que abren la posibilidad de un replanteamiento de lo expuesto. Esta provisionalidad está ausente de las poéticas universalistas, que no se construyen sobre el yo ni sobre la figura de autor.

Pero el rasgo que más certeramente contribuye a reafirmar la noción de autor en el género es la autocaracterización del mismo en el texto. Consciente de que el interés de la obra recae en su nombre propio, se permite construir una imagen de sí mismo que navega entre las aguas del pretendido ejercicio de sinceridad y la voluntad de proporcionar al público lector una figura autorial reconocible, permitiendo estudiar la imagen que el escritor va configurando de su propio colectivo -a partir de la suma de las manifestaciones individuales- en cada época.

En el plano más textual, esta cualidad se puede expresar por medio de la enunciación y, de forma más evidente, por medio de referencias, descripciones o la inclusión de momentos narrativos, a menudo en forma de anécdotas biográficas, que configuran como personaje al autor. Son los momentos de mayor información biográfica de los textos, de mayor referencialidad hacia el autor como individuo extratextual. En los ejemplos a los que estamos refiriendo estas cuestiones la selección es demasiado breve para notarlo, aunque Gil de Biedma menciona lo sacrificado de la escritura, ofreciendo un indicio para considerar una imagen de autor reflejada alejada del poeta inspirado.

Un ejemplo más interesante desde esta perspectiva es el siguiente fragmento de Antonio Colinas:

Iban avanzando los días y los encuentros, días decisivos en los que para el joven poeta que nacía todo consejo sobre una palabra, sobre un verso, sobre un autor, era delicada y casi diplomáticamente expuesto por el maestro: "Yo cambiaría esa palabra final, pues el poema no se cierra con intensidad", "Deja de hacer sonetos por una temporada", "Lee cuanta poesía puedas y libros de todos los géneros...". Son simples y entrecortados recuerdos de aquellos primeros días. Frases sin aparente importancia, pero muy decisivas en un momento determinante, como era el de la primera formación de un escritor, el de sus dieciocho años.

Luego -ya lo he afirmado en alguna otra ocasión- la vida literaria, las publicaciones, la vida de cada día, eran otra historia. Cada cual debía superar su prueba y pechar con los espinos y las dudas de su propia vocación literaria, que en mi caso estuvo llena de ellos, por lo que hubo de renuncia. Cada cual debía abrir su camino y hacerse responsable de su obra (Colinas, 2008: 225).

En este fragmento recuerda Colinas los consejos dados en los días primeros de su actividad poética por Vicente Aleixandre y las dificultades inherentes al desa-

15 Para profundizar en la reflexión acerca de la sujeción de la poética explícita a su contexto es interesante acudir al artículo de Arturo Casas, "La función autopoética y el problema de la productividad histórica" (2000). 
rrollo y consolidación de la misma, configurando - de forma consciente o de forma inconsciente- una imagen de autor que es la que ofrece a su público por medio de la publicación controlada del texto.

Partimos del último de los rasgos presentados, la presencia de anécdotas biográficas, para profundizar en otra de las cuestiones nucleares que plantean las poéticas en relación con la problemática del autor. Se hace necesario, en primer lugar, volver a retomar con mayor atención la legitimación del género debido a la identificación entre autor textual y autor biográfico. Esta cuestión se inscribe en la problemática planteada por los géneros autobiográficos y, en menor medida, en los llamados géneros del yo, entre los que se incluye la autoficción que tanta atención está recibiendo en este momento. La autobiografía, como la poética explícita, sólo tiene sentido en función de quién habla.

Puede acudirse para analizar la constitución del autor en los géneros de tipo autobiográfico al texto clave "El pacto autobiográfico", de Philippe Lejeune, recogido en 1994 en El pacto autobiográfico y otros ensayos. La exposición de Lejeune, una vez caracterizado el género autobiográfico desde sus rasgos primarios esenciales, gira en torno a la propuesta de la necesidad de un pacto por el que se entiende que el lector acepta la identidad del yo gramatical y el autor biográfico, y acepta asimismo tomar como verdad, con todas las matizaciones necesarias que esta afirmación reclama, lo narrado en el texto ${ }^{16}$. Del mismo modo que en la autobiografía, las poéticas explícitas deben regirse por este pacto de veracidad, debido a las fuerzas que impone la estricta sujeción a un autor concreto y reconocible.

La identidad entre yo gramatical y autor biográfico, reconocida por el lector con anterioridad a la recepción del texto, es puesta en evidencia no sólo por el nombre propio que remite a un autor conocido, sino también por otros elementos, como pueden ser el medio de difusión (la editorial o colección en que aparece publicado el texto; las antologías poéticas), el título del mismo ${ }^{17}$ (usualmente "Poética", construcciones que incluyen este término o títulos que adelantan el contenido literario) o incluso el conocimiento o intuición previos sobre el género que pueda tener el lector. ¿Cómo conjugar esta identificación con la afirmación de Roland Barthes de que el autor se construye en el discurso, y no es previo a él? Según el filósofo francés, el "escritor moderno nace a la vez que su texto" (Barthes, 1987b: 68-69). No hay una línea temporal que sitúe esta instancia en un momento previo a la escritura, sino que se "traza un campo sin origen, o que, al menos, no tiene más origen que el mismo lenguaje, es decir, exactamente eso que no cesa de poner en cuestión todos

16 Respecto a esta cuestión, Francisco Rodríguez afirma que la "marca de referencialidad que carga la tradición en el género que examinamos se debe en mucho a su asociación con el género histórico de la biografía y a un aspecto pragmático que lo caracteriza: la correferencialidad entre autor, enunciador textual y héroe, lo que provoca una ilusión de referencialidad muy preciada desde el punto de vista de la constitución verosimilizante del género. Se evidencia que en el horizonte de expectativas del lector, el género autobiográfico mantiene una elevada carga de referencialidad, heredera de esa tradición que estima el género como portador de la verdad del escritor. En ese mismo horizonte ronda la certidumbre de descubrir en los escritos autobiográficos la identidad del escritor. A pesar de que como demuestra Gusdorf, el héroe de la autobiografía es otro sujeto, aquel anhelado por la inestable memoria del sujeto-escritor, su yo-proyección, su 'autos' deseado y corregido para un ansioso lector" (Rodríguez, 2000: 19).

17 Sería interesante continuar la reflexión acerca del papel de un escritor de poética explícita ante el rótulo "Poética" que suele encabezar los textos, sobre todo en antologías poéticas. ¿Cómo se sitúa el autor frente a ese título, fuertemente impuesto desde fuera? ¿Lo acepta? ¿Lo desafía? Ese título lo instaura desde fuera como autor y da validez e importancia previas a las palabras que seguirán a continuación del mismo. 
los orígenes" (Barthes, 1987b: 69). Sin embargo, para las poéticas explícitas, parece patente la necesidad de un momento previo de construcción del autor, pues el lector debe leer el texto desde esa clave, sin que sea necesario tampoco volver a la estrecha concepción tradicional del autor. Como reflexiona Juan Zapata,

[s]i el autor no precede la obra, sino que es el resultado de un complejo proceso de construcción identitaria que no puede ser reducido ni a la existencia biográfica, como lo quería la historia literaria tradicional, ni a un elemento del discurso, como lo quería el estructuralismo, ¿cuál es entonces la relación que se establece entre el autor y su obra? Y más importante aún, ¿cuál es la naturaleza de dicha relación para la interpretación de un texto? (Zapata, 2011: 38).

La relación que se establece entre un autor y su obra se construye en dos sentidos opuestos. Por un lado, ya se ha insistido suficientemente en la necesidad de una imagen de autor previa, aunque sea un esbozo inexacto de la misma, que permita el surgimiento del género, la publicación de las obras y el reconocimiento del lector, que derive en su voluntad de recibir el texto. Por otro lado, el propio género es testimonio vivo de la construcción de la imagen autorial, del proyecto de autor, mostrando el esfuerzo del autor por dar una determinada imagen de sí mismo, que lo alinee o lo enfrente con la imagen dominante en el momento particular en que se desenvuelve.

La cuestión que plantea Zapata acerca de cómo debe comprenderse la relación entre autor e interpretación del texto debe tomarse con precaución en el estudio de las poéticas. Pese a que se ha desestimado la opinión del autor sobre su obra como guía interpretativa de la misma, y que la crítica ha dejado hace décadas de indagar en la voluntad última del autor como piedra de toque, las poéticas explícitas parecen animar al lector a realizar una lectura o relectura guiada por la mano del escritor al ofrecer unas claves interpretativas particulares. Por ello, debe incidirse en que la problemática de la interpretación de la obra a partir de las poéticas debe entenderse del mismo modo que la interpretación a partir de la voluntad del autor. Es decir, su influencia en la interpretación debe ser mínima. Fundamentalmente porque esas claves interpretativas se corresponden con un autor construido -no sólo por medio de mecanismos estructurales, como quería Barthes-, en el cual la veracidad expositiva debe ser cuestionada, sino porque topamos con la imposibilidad lógica de aplicar la interpretación del autor, aunque sea este interés lo que da origen a la aparición del género. No se trata sólo de tener en cuenta esta tendencia a la autorialidad construida, sino también constatar de nuevo que el autor no es, muy a menudo, su mejor lector.

Manuela Romo, en su artículo "Teorías implícitas y creatividad artística", ha llamado la atención sobre un fenómeno que afecta a la escritura de las poéticas explícitas y otros géneros afines, la búsqueda de consonancia cognitiva, que

nos exige reestructurar el pensamiento y cambiar la conducta. Hay ocasiones en que no se puede preservar la teoría por la existencia de conflictos repetidos con la experiencia que nos obligan a hacer revisiones o incluso a sustituirla por otra que eventualmente cumpla mejor su función (Romo, 1998: 13).

Se advierte que el pensamiento contenido en una poética explícita puede ser divergente con la práctica poética, alterándose la primera para adecuarse a la 
obra ya construida o en proceso. La veracidad de la poética explícita no se sostiene en esos casos por su fidelidad al autor sino por su coherencia respecto de la obra previa. A su vez, esta relación de dependencia puede ocurrir en sentido inverso, adaptándose la obra literaria a lo previamente expuesto bajo formas ensayísticas en las poéticas explícitas. Este fenómeno llama la atención sobre, y contribuye a romper, la relación interpretativa cuestionada por Zapata a partir de Barthes, eliminando la figura del autor biográfico para terminar, como quería el pensador francés, en una relación entre textos que crea la ilusión de una perspectiva autorial. Esta búsqueda de consonancia cognitiva por medio de la cual el autor biográfico intenta resolver las contradicciones en su seno de teoría y práctica, reforzando de paso la identidad autorial por medio del ofrecimiento artificial de una imagen monolítica o sin excesivas aristas, debe tenerse en cuenta al valorar la noción de autor ${ }^{18}$.

Otra de las cuestiones en torno al autor planteadas por Michel Foucault cobra especial interés en los textos de tipo autobiográfico. Se trata de la problemática del nombre del autor, respecto del cual Philippe Lejeune, a la hora de caracterizar la autobiografía, planteó la imposibilidad de la anonimia en un texto que se funda sobre el reconocimiento del autor. Estas son sus palabras: "[r]esulta imposible que la vocación autobiográfica y la pasión de anonimato coexistan en el mismo ser" (Lejeune, 1994: 72), perfectamente aplicables al caso de las poéticas explícitas.

Es el nombre propio, para Lejeune, entidad existente antes todavía que la primera persona del discurso, convirtiéndose en aquello que reúne el sujeto del enunciado y el sujeto de la enunciación. Es lo que, en su virtud unitiva o por lo menos referencial de lo extratextual y lo intratextual, sostiene el interés del texto. En relación con esta cuestión, Gerard Genette propuso en Umbrales el término onimato para valorar este fenómeno:

El nombre de autor puede en efecto asumir tres condiciones principales, sin contar con algunos estados mixtos o intermedios. $\mathrm{O}$ bien el autor firma con su nombre real [...] o bien firma con un nombre falso, fingido o inventado: es el seudonimato; o no firma de ninguna manera, es el anonimato. Es tentador acuñar, sobre el modelo de los otros dos, el término onimato [...]. El onimato obedece a una razón a veces más fuerte o menos neutra que la ausencia del deseo de darse un seudonimato: es evidentemente el caso, ya evocado, en que una persona ya célebre produce un libro cuyo éxito podrá deberse a esa celebridad previa. El nombre no es entonces una simple mención de la identidad ("el autor se llama Fulato de tal"), es el medio de poner al servicio del libro una identidad, o más bien una "personalidad" (Genette citado en Aparicio Maydeu, 2015: 181).

Como indica Foucault, ese nombre, el que aparece en la portada del libro, remite al autor por lo menos en el sentido de un sujeto de responsabilidad jurídica, quien

18 Juan Zapata no sólo se detiene en este aspecto, sino que propone el estudio aunado tanto de texto como de paratexto para determinar la imagen de autor: "Si bien es cierto que el discurso de ficción exige unas estrategias de análisis particulares, éste no deja de remitirnos siempre al espacio de tomas de posiciones en un campo y, en cuanto tal, a una estrategia autorial. De ahí que la tarea consista más bien en establecer la manera en que los despliegues de la figura autorial, el textual y el paratextual, coinciden, pues ambos se remiten a una misma posición de origen" (Zapata, 2011: 49). En nuestra opinión, la imagen de autor que ofrecen ambos tipos de textos, como hemos señalado, en ocasiones es divergente. 
se hace cargo de lo afirmado. Pero su nombre, el nombre de autor, no es un nombre propio como los demás:

si descubro que Shakespeare no nació en la casa que hoy visitamos, ésa es una modificación que evidentemente no va a alterar el funcionamiento del nombre de autor; pero si se demostrara que Shakespeare no escribió los Sonetos que se consideran suyos, ése es un cambio de otro tipo: no deja indiferente el funcionamiento del nombre de autor. Y si se probara que Shakespeare escribió el Organon de Bacon simplemente porque fue el mismo autor el que escribió las obras de Bacon y las de Shakespeare, ése es un tercer tipo de cambio que modifica íntegramente el funcionamiento del nombre de autor. El nombre de autor no es pues exactamente un nombre propio como los demás (Foucault, 2010: 19).

Esta problemática se ve multiplicada en las poéticas explícitas, en tanto que nos encontramos con textos que voluntariamente buscan una determinada imagen de autor. Por tanto, ésta no surge ya del texto, sino de una manipulación consciente de determinados agentes, entre ellos el yo autor biográfico, que lo determina cada vez con mayor frecuencia. La reflexión de Foucault explica por lo demás la necesaria imposibilidad de anonimia de las poéticas explícitas: "el nombre de autor funciona para caracterizar un determinado modo de ser del discurso", indicando que "se trata de una palabra que debe ser recibida de cierto modo y que en una cultura dada debe recibir un estatuto determinado" (Foucault, 2010: 20). Es de hecho el nombre del autor el seguro que permite la publicación editorial de las poéticas explícitas, el garante de su éxito comercial que asegura la viable existencia de este género.

Como señala José María Pozuelo Yvancos en referencia a las propuestas de Paul de Man acerca de la autobiografía, "no es el referente quien determina la figura, sino [...] que es la figuración la que determina el referente" (Pozuelo Yvancos, 2006: 37). En definitiva, vamos encaminándonos hacia la idea de que el autor es un autor construido, de forma similar a como pueda serlo en una obra puramente literaria. Nos adentramos así en un cierto grado de ficcionalización del autor, que constata la distancia del escritor -individuo biográfico- con el autor, que parece como si creciera al margen del primero, que lo crea, imponiendo una distancia. Esa imagen de autor será la que pueda conectarse con la función-autor propuesta por Foucault, la que recoja sus exigencias. En las poéticas explícitas contemporáneas se percibe bien esta distancia, aún en la paradoja de ser textos construidos sobre una voluntad referencial.

\section{Una perspectiva sociológica}

Más allá de los mecanismos estrictamente textuales expuestos por Roland Barthes y Michel Foucault en sus respectivas reflexiones "La muerte del autor" y ¿Qué es un autor?, la introducción de una perspectiva sociológica facilita la comprensión de determinadas cuestiones que atañen al autor presentes en las poéticas explícitas. Algunas de las más relevantes son las siguientes:

a) alta vinculación con las circunstancias del mercado editorial. Las poéticas explícitas surgen y son favorecidas por el mercado editorial, representando el consu- 
mismo cultural en su propia multiplicación. Prácticamente todos los autores tienen poéticas -que son exigidas por antólogos, editores, etc.- y cada autor puede llegar a tener numerosísimas poéticas a lo largo de los años. Su producción, por tanto, se enmarca dentro de la lógica del consumo y de la moda (ver por ejemplo los planteamientos de Zygmunt Bauman en La cultura en el mundo de la modernidad líquida, 2013), que plantea la caducidad de un texto y la necesidad de su sustitución periódica, en la vivencia de un presente eterno ${ }^{19}$.

b) alta vinculación con los medios de comunicación. Las poéticas explícitas reclaman al autor como autor, apuntalan ese nombre propio que hace referencia al escritor biográfico, por lo que son un excelente medio de propaganda, de recordatorio de la existencia de ese autor. Como se ha mencionado, muchas poéticas explícitas -casi todas las que no aparecen en antologías poéticas- se publican como columnas periodísticas, entrevistas, o se difunden en forma de charlas y conferencias. La presencia en los medios de comunicación de un nombre de autor revitaliza sin duda la venta de sus obras; la lógica nos dice que muchas poéticas se escribirán con este pensamiento en mente.

c) alta vinculación con la existencia de círculos y camarillas literarios. En uno de los pequeños fragmentos citados del poeta Jaime Gil de Biedma encontramos la alusión a un "nosotros". Esta indicación limita el panorama editorial, establece reconocimientos, alianzas. La poética explícita por medio de estas alusiones permite que el autor se sitúe en un espacio completo de la totalidad. Pero también la presencia o ausencia en antologías y medios sirve para apoyar o relegar al olvido determinados autores del panorama literario del momento.

Pierre Bourdieu en Las reglas del arte. Génesis y estructura del campo literario (1992) agitó la consideración de los sistemas de creación y recepción de las obras de arte desde una perspectiva sociológica. Juan Zapata retoma a partir de las reflexiones de Bourdieu sobre el campo literario la división entre dos grandes grupos que mantienen una serie de fuerzas en tensión:

1) la instancia de los productores, que designa esencialmente a los autores, y 2) las instancias de reproducción y legitimación, que agrupan tanto a los actores cuya función es mantener un discurso sobre la literatura (esencialmente la crítica literaria en todas sus formas: pública o privada, oral o escrita) como a las instancias de orden socio-económico (Zapata, 2011: 44-45).

Desde nuestra comprensión, las poéticas explícitas son de los escasos ejemplos que forman parte de los dos campos: son creadores que a la vez son críticos de sí mismos, del panorama literario y de la literatura en general. Los conflictos que esta

19 En este diagnóstico coinciden numerosos pensadores. Por ejemplo, Gilles Lipovetsky se había manifestado del mismo parecer en Los tiempos hipermodernos, al afirmar lo siguiente: "En la hipermodernidad ya no hay más opción ni más alternativa que evolucionar, que acelerar la movilidad para no ser adelantados por la 'evolución': el culto a la modernización técnica ha superado a la glorificación de los fines y los ideales" (Lipovetsky, 2014: 60). Y también: "Se consolidan sociedades reorganizadas por la lógica e incluso por la temporalidad de la moda, vale decir por el presente, que sustituye la acción colectiva por la felicidad privada, la tradición por el movimiento, las esperanzas del futuro por el éxtasis de la novedad perpetua. Nace toda una cultura hedonista y psicologista que incita a la satisfacción inmediata de las necesidades, estimula la urgencia de los placeres, halaga la expansión de uno mismo, pone en un pedestal el paraíso del bienestar, la comodidad y el ocio. Consumir con impaciencia, viajar, divertirse, no renunciar a nada: tras las políticas del porvenir ha venido el consumo como promesa de un presente eufórico" (Lipovetsky, 2014: 64). 
doble dimensión plantea a la hora de considerar los textos no son pocas. El autor convertido en crítico no sólo plantea los problemas señalados anteriormente, sino que se encuentra en una posición a la vez productora y sancionadora.

También desde una perspectiva sociológica parece encontrarse una respuesta a la afirmación de que el autor se construye en el texto. Frente a esta posición, y como ya hemos ido atisbando, Juan Zapata concluye que la construcción del autor debe ser previa al texto. Vemos en sus planteamientos cómo va cambiando la propia noción a estudiar, no hablándose ya de autor sino de todo un proceso que configura lo que entendemos como autor, y que, parece deducirse, no tiene fin en tanto que dicho proyecto no sólo se ve alterado por el sujeto - con lo que finalizaría con la muerte de éste- sino también con otros elementos diversos del panorama editorial que lo sobrepasan: público lector, crítica, instituciones académicas y educativas, etc.

La construcción de la imagen de autor es por tanto una actividad previa al texto. En diálogo con Pierre Bourdieu, Ruth Amossy y Dominique Maingueneau, Juan Zapata afirma que la problemática del autor no debe plantearse tan sólo en la preocupación por solucionar problemas formales de construcción del texto, sino también en cuestiones relacionadas con la constitución del autor previa a la escritura del texto,

como la necesidad de proveerse de un rol, de una imagen, de una identidad escenográfica en función del repertorio de posturas existentes en el campo. Al adoptar una posición en el campo, el escritor, dirá José-Luis Díaz, no "responde únicamente a preguntas del tipo: ¿cómo escribir? ¿Cómo imponer su voz? O ¿qué género elegir? Sino también a la pregunta, aún más amplia y que engloba a todas las otras, ¿quién ser?: quién ser en tanto escritor que ocupa un lugar en la escena literaria, pero también quién ser en tanto hombre (Amossy y Maingueneau, citados en Zapata, 2011: 46).

Este planteamiento entra directamente en conflicto con Barthes y Foucault, que postulan la construcción del autor en el momento mismo de la escritura. Barthes negaría sin duda la última pregunta propuesta por José-Luis Díaz, tal como se desprende del siguiente fragmento: "como sucesor del Autor, el escritor ya no tiene pasiones, humores, sentimientos, impresiones, sino ese inmenso diccionario del que extrae una escritura que no puede pararse jamás: la vida nunca hace otra cosa que imitar al libro, y ese libro mismo no es más que un tejido de signos, una imitación perdida, que retrocede infinitamente" (Barthes, 1987b: 70).

Pero también se enfrenta, aplicado a los textos autobiográficos y las poéticas explícitas, con el Philippe Lejeune de El pacto autobiográfico. Lejeune plantea la existencia previa del autor de autobiografías precisamente por la necesidad del nombre propio, prácticamente considerado como signo del autor, que dé sentido al nuevo texto. Por tanto, el autor es previo al texto, pero ¿qué configura entonces al autor? Lejeune sugiere que el autor lo es en tanto que tiene una obra. Es la obra previa, ya terminada, la que inviste al autor de dicha categoría.

Resulta llamativa la disparidad de perspectivas resultante de la confrontación de las diferentes disciplinas académicas que han abordado la problemática del autor, encontrándonos ejemplos de las tres opciones temporales de constitución del autor como tal: previa al texto (perspectiva sociológica), simultánea al texto (perspectiva filosófica) y posterior al texto (perspectiva desde la teoría literaria). 
Continúa Zapata planteando algunas de las cuestiones que debe resolver el autor antes de escribir su obra, y que van constituyendo, adensando, su cualidad autorial:

Digamos entonces que, mucho antes de empezar a escribir, de tratar el problema de los géneros, del estilo o de los temas que tocará su obra a venir, el aspirante a autor hace frente al problema de su identidad, de su personalidad literaria, problema que se encuentra, si bien es cierto, íntimamente ligado a la adopción de un sistema de enunciación formal. Él debe construirse como escritor, definir su postura frente a los otros, pues sólo ésta le permitirá ser reconocido tanto al interior como al exterior del campo. Y puesto que el autor no existe en tanto no sea reconocido como tal, su existencia dependerá entonces de su capacidad de hacerse notar, de hacerse ver, de crear una identidad reconocible por el público. Pues, hay que decirlo, adquirir el derecho a hacer parte del campo no sólo consiste en adquirir y comprender sus reglas de funcionamiento, sus valores y sus códigos de expresión -interiorizados en lo que Bourdieau llama habitus-, sino que también en adquirir una postura, una conducta, una identidad escenográfica (Zapata, 2011: 47).

Esta extensa cita reconduce el planteamiento acerca del reconocimiento del autor. Éste depende de un primer plano individual donde el escritor construye su figura autorial, para, a continuación, someterla al público. Será éste el que otorgue finalmente el estatus de autor, por medio del reconocimiento del conjunto de sus rasgos -ya no estrictamente textuales-. Podría leerse entonces desde una nueva perspectiva la famosa sentencia de Roland Barthes, "el nacimiento del lector se paga con la muerte del Autor" (Barthes, 1987b: 71), del siguiente modo: el nacimiento del lector permite el nacimiento del autor.

La problemática del nombre propio que hemos abordado desde la teoría literaria y desde la filosofía ha recibido atención también desde la perspectiva sociológica. Confrontando su discurso en torno al autor con el de Foucault, Zapata retoma en "Muerte y resurrección del autor. Nuevas aproximaciones al estudio sociológico del autor" (2011) la peculiaridad del nombre propio autorial frente al nombre propio común. Si Foucault destaca la importancia del nombre de autor, con significaciones propias y por tanto no reducible a un mero elemento del discurso, que funciona como elemento relacional entre diferentes textos, entre los que establece unos lazos de filiación, y que realza un determinado tipo de discurso imponiendo un tipo de recepción determinada (Foucault, 2010: 20), Zapata reafirma la importancia del nombre de autor en términos de negociación de poder o influencia en el panorama literario:

Pero si bien es cierto que el nombre autor ejerce una función clasificatoria, no se reduce únicamente a ésta. En la operación misma de clasificación, de agrupar y excluir ciertos textos bajo un solo nombre, está ya de por sí la exigencia de la supervivencia, de la conservación. El crítico que así se aproxima y manipula ciertos textos, tiene ya la convicción de que éstos no deben ser recibidos como una palabra corriente, ordinaria, sino que están destinados a sobrevivir en el mundo del lenguaje. Les concede un valor y una autoridad especial y, por lo tanto, señala un cierto modo de recepción del discurso literario (Zapata, 2011: 40). 
Ciertamente, Foucault había contribuido a desplazar el lugar del autor en el texto del espacio central discursivo donde lo situaba Barthes abriendo el espacio al estudio sociológico de algunos aspectos del mismo:

el nombre de autor no va como el nombre propio desde el interior de un discurso al individuo real y exterior que lo produjo, sino que, de alguna manera, corre en el límite de los textos, que los recorta, que sigue sus aristas, que manifiesta su modo de ser o que al menos lo caracteriza. Manifiesta el acontecimiento de un conjunto determinado de discurso, y se refiere al estatuto de ese discurso en el interior de una sociedad y en el interior de una cultura (Foucault, 2010: 21).

Por tanto, la poética explícita posee bastantes elementos para reforzar la condición del nombre de autor -lo hace doblemente, por el peso del nombre de autor y por las características del género- en tanto que construye el modo en que recibimos los textos literarios, anticipando no sólo un modo de lectura sino una serie de rasgos que esperamos encontrar, o sugiriendo una línea interpretativa particular.

\section{Conclusiones}

Los resultados de este trabajo muestran la idoneidad de las poéticas explícitas para explorar la figura del autor, debido al adensamiento autorial del género que lo convierte en vehículo idóneo del autor y a su vez en campo adecuado para explorar sus manifestaciones. La individualidad, la provisionalidad, la escritura del yo o la problemática en torno al nombre propio aparecen como puntos clave a tener en cuenta. Se percibe asimismo que la idea del autor como dador de sentido ha sido desechada, lo que en las poéticas explícitas se refleja en una pérdida de su función de guía interpretativa de los textos literarios. Sin embargo, a la vez, el reconocimiento de la existencia de una imagen construida del autor -por otros y por sí mismo- sí condiciona la interpretación de la obra literaria y de la poética explícita, incluso aunque la construcción de la imagen de autor no sea consciente en el escritor, debido a fenómenos como el de la búsqueda de consonancia cognitiva.

En conclusión, nuestra investigación ha constatado que las poéticas explícitas suponen un discurso verdaderamente constructor de la imagen y proyecto de autor. El lector recibe explícitamente dicha imagen, por lo que puede entenderse a la vez, sin contradicción, la imagen de autor como previa al texto en su elemento de proyecto y a la vez como construida en el texto -aunque no sólo en él- mediante mecanismos discursivos que pueden ser analizados. Desde este punto de vista puede reunirse el discurso post-estructuralista de Barthes y Foucault con la perspectiva sociológica última en sus acercamientos a la figura del autor.

\section{Obras citadas}

Alberca, Manuel, El pacto ambiguo. De la novela autobiográfica a la autoficción, Madrid, Biblioteca Nueva, 2007.

Aparicio Maydeu, Javier, La imaginación en la jaula. Razones y estrategias de la creación coartada, Madrid, Cátedra, 2015. 
Badía Fumaz, Rocío, "Las poéticas explícitas como género", Rilce. Revista de literatura, 34.2 (2018), pp. 607-628.

—, "Las poéticas explícitas de Antonio Colinas y José Ángel Valente”, Madrygal, 18 (2015), pp. 161-170.

Barthes, Roland, "Escribir, ¿un verbo intransitivo?”, en El susurro del lenguaje. Más allá de la palabra y la escritura, Barcelona, Paidós, 1987a, pp. 23-33.

—, "La muerte del autor", en El susurro del lenguaje. Más allá de la palabra y la escritura, Barcelona, Paidós, 1987b, pp. 65-71.

Bauman, Zygmunt, La cultura en el mundo de la modernidad líquida, Madrid, Fondo de Cultura Económica, 2013.

Bourdieu, Pierre, Las reglas del arte. Génesis y estructura del campo literario, Barcelona, Anagrama, 1995.

Casas, Arturo, "La función autopoética y el problema de la productividad histórica", en José Romera Castillo y Francisco Gutiérrez Carbajo (eds.): Poesía histórica y (auto)biográfica (1975-1999), Madrid, Visor, 2000, pp. 209-218.

Colinas, Antonio, "El silencio de Vicente Aleixandre", en El sentido primero de la palabra poética, Madrid, Siruela, 2008, pp. 219-227.

Díaz, José-Luis, "Les scénographies auctoriales romantiques et leur "mise en discours", en Pascale Delormas, Dominique Maingueneau y Inger Østenstad (eds.): Se dire écrivain. Practiques discursives de la mise en scène de soi, Limoges, Lambert-Lucas, 2013, pp. 29-50.

Fazio, Silvina Celeste, "La escritura ensayística como autoconfiguración: crítica y autobiografía en Efectos personales de Juan Villoro", Taller de letras, 46 (2010), pp. 21-29.

Foucault, Michel, ¿Qué es un autor?, Córdoba (Argentina), El cuenco de plata / Ediciones Literales, 2010.

Gil de Biedma, Jaime, "Poética”, en Leopoldo de Luis (ant.): Poesía social, Madrid, Alfaguara, 1965, pp. 355-356.

_, Las personas del verbo, Barcelona, Barral Editores, 1975.

Jarillot Rodal, Cristina, Manifiesto y vanguardia, Bilbao, Universidad del País Vasco, 2010.

Lejeune, Philippe, El pacto autobiográfico y otros estudios, Madrid, Megazul / Endymión, 1994.

Lipovetsky, Gilles y Jean Serroy, La estetización del mundo. Vivir en la época del capitalismo artístico, Barcelona, Anagrama, 2014.

Lipovetsky, Gilles y Sébastien Charles, Los tiempos hipermodernos, Barcelona, Anagrama, 2014.

Maingueneau, Dominique, "Escritor e imagen de autor", Tropelías, 24 (2015), pp. 17-30.

Meizoz, Jérome, Posturas literarias. Puestas en escena modernas del autor, Bogotá, Universidad de los Andes, 2015.

Pérez Fontdevila, Aina y Meri Torras Francés (eds.), monográfico "La autoría a debate: textualizaciones del cuerpo-corpus", Tropelías, 24 (2015).

Pérez Fontdevila, Aina y Meri Torras Francés (eds.), Los papeles del autor/a. Marcos teóricos sobre la autoría literaria, Madrid, Arco / Libros, 2016.

Popovic, Pierre, “Les deux 'arts poétiques' de Paul Verlaine”, Études françaises, 29.3 (1993), pp. 103-121.

Pozuelo Yvancos, José María, De la autobiografía. Teoría y estilos, Barcelona, Crítica, 2006.

—, Las ideas literarias (1214-2010), Madrid, Crítica, 2011.

Provencio, Pedro, Poéticas españolas contemporáneas. La generación del 50, Madrid, Hiperión, 1988a. 
—, Poéticas españolas contemporáneas. La generación del 70, Madrid, Hiperión, 1988b.

Rodríguez, Francisco, "El género autobiográfico y la construcción del sujeto autorreferencial”, Filología y lingüística, 36.2 (2000), pp. 9-24.

Romo, Manuela, "Teorías implícitas y creatividad artística", Arte, individuo y Sociedad, 10 (1998), pp. 11-28.

Ruíz Pérez, Pedro, La rúbrica del poeta. La expresión de la autoconciencia poética de Boscán a Góngora, Valladolid, Universidad de Valladolid, 2009.

Vattimo, Gianni, "Vocación ontológica de las poéticas del siglo XX", en Gianni Vattimo, Poesía y ontología, Valencia, Universidad de Valencia, 1993.

Zapata, Juan, "Muerte y resurrección del autor. Nuevas aproximaciones al estudio sociológico del autor", Lingüística y literatura, 60 (2011), pp. 35-58.

- La invención del autor. Nuevas aproximaciones al estudio sociológico y discursivo de la figura autorial, Medellín, Universidad de Antioquía, 2014. 